\title{
SERVIÇO SOCIAL, CONDIÇÕES DE TRABALHO \\ NO SISTEMA PENAL E FORMAÇÃO \\ PROFISSIONAL: NOTAS EM PROL DE UM \\ DEBATE NECESSÁRIO*
}

\author{
Valeria Lucilia Forti \\ Thamires Pereira dos Santos
}

As Diretrizes Curriculares da Associação Brasileira de Ensino e Pesquisa em Serviço Social (ABEPSS), datadas de 1996, expressam uma lógica curricular que relaciona três núcleos de fundamentos, objetivando formular um conjunto de conhecimentos articulados, melhor dizendo, indissociáveis e essenciais à formação profissional do assistente social. ${ }^{1}$ Entre os três núcleos que compõem as referidas Diretrizes Curriculares da ABEPSS, há o que se refere ao trabalho e às relações sociais, o que implica assegurar um amplo conteúdo pedagógico para a formação profissional, que vai desde os conteúdos que contemplem o trabalho como categoria que suscita o mundo humano aos que se dirigem ao trabalho assalariado e sua atual morfologia. ${ }^{2}$ Nesse ponto, se encontram as discussões acerca do Serviço Social como especialização do trabalho coletivo e das particularidades da inserção do assistente social, uma vez que é trabalhador assalariado inserido nos processos de trabalho do cotidiano institucional, seja público ou privado. Por conseguinte, tais discussões incluem a atribuição do supervisor de campo do estágio obrigatório à formação profissional e do docente inserido em instituição de ensino, responsável por lecionar diferentes disciplinas e pela orientação acadêmica do estágio curricular obrigatório. ${ }^{3}$

DOI - 10.29388/978-65-86678-15-4-0-f.137-158

1 Utilizaremos essa única forma de gênero, visando favorecer a leitura, uma vez que a alternância recorrente pode tornar-se cansativa ao leitor/a.

2 A atual morfologia do trabalho vincula-se ao modo de sua exploração.

3 Não obstante ter diferentes nomeações, é uma das disciplinas que compõem a grade curricular da graduação em Serviço Social. 
O estágio curricular é atividade que deve comportar as necessárias reflexões teórico-práticas que também fundamentarão e balizarão as ações dos futuros profissionais, e isso supõe, em consequência, responsabilidade profissional em face da prestação de serviços aos usuários das instituições empregadoras. Observe-se que o Serviço Social é um segmento das ciências sociais em que o trabalho dirigido ao atendimento de diversos sujeitos que procuram diferentes instituições em busca de saciar alguma necessidade (material ou não) é característico. Como amplamente difundido na literatura profissional crítica, o assistente social dirige a sua ação profissional às múltiplas expressões da "questão social" ${ }^{\prime}$ e tem como área predominante de atuação as políticas sociais, apesar de não ser sua área exclusiva. Nesse processo, a contribuição do supervisor de campo do estágio em Serviço Social para a formação de futuros profissionais é, notoriamente, indispensável. Apesar disso, e mesmo que tenhamos consciência de que se trata de atribuição privativa do profissional, cabe-nos captar que é atividade que se coloca no bojo das alterações em curso no âmbito do trabalho, que, além de intensificarem, suscitam diferentes requisições aos assistentes sociais no cotidiano institucional. Como foi dito, é uma atividade que, no trabalho do assistente social, é definida como sua atribuição privativa, conforme art. $5^{\circ}$ da Lei 8.662, datada de 7 de junho de 1993, que regulamenta a profissão. Isso é referência, inclusive, no Código de Ética do Assistente Social vigente, conforme seu art. $4^{\circ}$, letra "e", que veda ao assistente social "permitir ou exercer a supervisão de aluno de Serviço Social em instituições públicas ou privadas que não tenham em seu quadro assistente social que realize acompanhamento direto ao aluno estagiário" (BRASIL, 2012).

Dessa maneira, torna-se possível perceber que o Serviço Social possui normativas que configuram referências e exigências ao trabalho do assistente social e à sua formação profissional, objetivando contribuir para a boa qualida-

4 Podemos considerar "questão social", conforme Netto (1989, 2001), o conjunto de problemas econômicos, sociais, políticos, culturais e ideológicos presentes na emersão da classe operária como sujeito sociopolítico no marco da sociedade burguesa. Indubitavelmente, hoje, ainda, são problemas presentes, uma vez que inerentes à sociedade capitalista, mas suas expressões corresponderem ao atual estágio desse modo de produção. Além das obras citadas, a respeito da "questão social", cabe-nos destacar a importância da consulta ao livro "A questão social no Brasil", de Gisálio Cerqueira Filho (1982), e a "Revista Temporalis" n. 3 (2001). 
de da formação profissional e dos serviços institucionais prestados aos usuários. Para tanto, considera o estágio um dos requisitos obrigatórios à formação profissional, o qual, como já explicitado, pressupõe o indispensável e pertinente contributo do assistente social supervisor de campo.

Diante do exposto - e evidenciando que aqui abordaremos parte de uma pesquisa realizada em uma secretaria penal do estado do Rio de Janeiro, área que tradicionalmente, além de comportar o Serviço Social entre os seus trabalhadores, ${ }^{5}$ manteve uma média de mais de 35 estagiários de Serviço Social, assegurando remuneração, seguro e transporte -, destacamos que, para nos aproximarmos de alguma compreensão do Serviço Social, é imprescindível considerarmos, pelo menos em linhas gerais, a dinâmica da sociedade na qual a profissão se situa. Dessa maneira, aqui, não obstante o caráter sintético da abordagem, iniciamos pela categoria trabalho, haja vista tratar-se do elemento fun-

${ }^{5}$ Para elaboração do presente texto, recorremos a dados da pesquisa em curso, intitulada "Ética, direitos, trabalho e Serviço Social: um estudo do sistema penal". A pesquisa conta com diferentes subprojetos, entre os quais o denominado "Ética e formação profissional: um estudo sobre o estágio curricular", do qual extraímos os dados referentes às entrevistas com os estagiários. Este subprojeto, que previmos prosseguir (aguardamos em face de nossa intenção de continuidade), pelo menos, por mais dois ou três anos, ou seja, até 2017/2018, teve que ser interrompido em decorrência do corte das bolsas destinadas ao estágio na secretaria penal do estado do Rio de Janeiro. Todavia, após esforços da equipe de trabalho no local, essa atividade deverá ser retomada em 2020 e, caso ocorra, os participantes do projeto/subprojeto de pesquisa serão convidados para discutirem com os supervisores os resultados alcançados, visando ao aprimoramento da formação profissional no local.

Neste texto, procuramos, apesar de sinteticamente, trazer alguns argumentos sobre a relação entre o atual contexto neoliberal, o sistema penal, o exercício e a formação profissionais do Serviço Social no mencionado espaço sócio-ocupacional, considerando algumas apreciações de alunos acerca da experiência de estágio obrigatório (alunos que à época estavam com o estágio em curso na secretaria penal do Rio de Janeiro e outros que eram egressos), já que a supervisão é parte do trabalho do assistente social, definida como competência privativa e essencial à formação de futuros profissionais da área. Para tanto, em decorrência do objetivo e dos limites deste texto, selecionamos alguns dados avaliados como essenciais, visando à reflexão acerca da condição carcerária no país e das condições de trabalho e formação, por meio do estágio supervisionado, dos assistentes sociais inseridos no sistema penal do Rio de Janeiro.

É indispensável esclarecer que, em decorrência da exigência de sigilo, além de não identificarmos os entrevistados, não denominaremos a instituição, precisamente. 
dante do ser social e atividade que constitui e caracteriza a existência humana. É também a fonte de satisfação das necessidades humanas e sua possibilidade histórica. O trabalho é um processo em que, por meio da ação humana, se efetiva o metabolismo entre o homem e a natureza. Diferentemente das atividades que se mantêm fixadas na condição das demais espécies, o trabalho foi base "dinâmico-estruturante" ${ }^{6}$ de um novo tipo de ser: o ser social. Uma categoria que apenas se tornou possível após certo grau de desenvolvimento do processo de reprodução do ser orgânico. É, portanto, um tipo de atividade que ultrapassa o mero condicionamento biológico, a adaptação ou submissão ao mundo ambiental. O trabalho é uma atividade que conta com a prévia-ideação para a objetivação do produto, ou seja, antes de ser materializado, o produto já era idealizado pelo seu executor.

Pode ser dito que a ação com finalidade consciente é a viabilizadora da ultrapassagem do animal para além da mera esfera da necessidade. Contudo, isso ocorre sem extinguir sua dimensão natural, orgânica e inorgânica, sua determinação biológica.

O fulcro do salto que permitiu a hominização do ser natural foi o trabalho e, nesse processo produtor de respostas às carências, os homens desenvolveram/desenvolvem novas capacidades, novas qualidades e novas necessidades.

O trabalho é também uma categoria social, pois se efetiva engendrando as relações sociais e por meio dessas próprias relações. Portanto, pode-se considerá-lo produtor e simultaneamente partícipe da sociabilidade - meio de transformação da natureza pelo qual o homem se constrói, constitui a sua individualidade e também a totalidade social da qual é parte (FORTI, 2016, p. 33).

O exposto aborda o trabalho gerador de valores úteis, ou seja, nos referimos a uma atividade eterna que cria produtos humanizados para satisfação das necessidades sociais e, simultaneamente, possibilita a autoconstrução do ser humano. Em qualquer formação social, o trabalho está presente, produzindo valores de uso, haja vista, como já explicitado, ser condição da própria existência humana, sua atividade livre e consciente.

A História é a substância da sociedade e compósito de esferas da vida social, a exemplo das relações de produção, de propriedade, da estrutura, da po-

6 Denominação utilizada por Lukács (1978). 
lítica, da vida cotidiana, da moral, da ciência e da arte. Aí se encontra o cenário de emersão da consciência e do conhecimento. Nossa referência é a um processo em que a realidade vai sendo desvendada e transformada pelo sujeito, na medida em que, simultaneamente, este se constrói como ser social. Aqui, nos referimos a um percurso em que a dimensão subjetiva vai sendo tocada, possibilitando a construção de um ser que vai adquirindo consciência e por ela sendo guiado; ou seja, um percurso em que não mais apenas instintos são identificados, uma vez que, apesar de não eliminados, estarão acompanhados da capacidade que possibilita responder às necessidades naturais, podendo torná-las sociais, históricas. O homem, ser social, jamais poderá se separar da sua dimensão biológica, assim como essa dimensão orgânica incorpora a natureza inorgânica, não obstante a superar. Todavia,

O ser social [...] tem um desenvolvimento no qual essas categorias naturais, mesmo sem jamais desaparecerem, recuam de modo cada vez mais nítido, deixando o lugar de destaque para categorias que não têm na natureza sequer uma analogia. É o que ocorre no caso da circulação de mercadorias, em que determinadas formas próximas à natureza (o gado como meio geral de troca) são substituídas pelo dinheiro, que é puramente social [...]; assim acontece na revolução industrial, em que a introdução das máquinas faz com que o homem e sua capacidade de trabalho não sejam mais os fatores determinantes do trabalho, que o próprio trabalho humano seja desantropomorfogizado etc. (LUCKÁS, 2012, p. 319).

Voltando-nos a esta última citação de Lukács (2012), observaremos que, não obstante eterno, o trabalho é atividade humana histórica que incorpora condicionamentos ao longo do tempo. Hoje, na sociedade capitalista, fundamentalmente, mostra-se submetido ao capital como produtor de mercadorias, ou seja, como produtor de algo que será consumido como valor de uso por outro(em) e produzirá a mais valia para o proprietário dos meios de produção. Isso porque, nessa sociedade, o modo de produzir fundamenta-se na propriedade privada dos meios de produção e tais meios não estão disponíveis a todos; ao contrário, encontram-se restritos aos poucos proprietários que impõem condições aos trabalhadores, que deles dependem para subsistirem por meio do salário recebido pela venda da sua força de trabalho. Na sociedade capitalista, o produto final do trabalhador se apresenta como meio de troca, como produto que deve ser medido, fundamentalmente, pela quantidade de trabalho nele depositado. Aliás, a alusão à força de trabalho significa a venda de algo que será consumido como mercadoria também. Diante desse fato, deve-se destacar que 
nessa formação social a riqueza não se expressa pelo "ser", pelo enriquecimento humano decorrente das possibilidades de subjetivação do que foi objetivado pelas conquistas civilizatórias da humanidade, pelas possibilidades de enriquecimento humano em face das conquistas humano-genéricas; diferentemente disso, a riqueza significa expressão do "ter", do acúmulo de mercadorias e, portanto, de capital. Esse é um processo que estabelece uma relação fetichizada, ou seja, que encobre a relação social que efetiva a produção da mercadoria.

No modo de produção capitalista, a força de trabalho, ao ser consumida, produz um produto que não lhe pertence, restando-lhe dar continuidade ao processo de venda de sua única mercadoria, para que consiga adquirir o salário e, assim, manter a sua subsistência e de sua família. Dessa maneira, ao trabalhador cabe não só produzir e reproduzir suas necessidades vitais e de sua família, mas produzir e reproduzir o referido modo de produção, sendo o capital uma relação social, uma relação entre as classes sociais.

Considerando o exposto, não é difícil a inferência das inúmeras contradições e conflitos oriundos dessa relação entre as classes sociais; ou seja, é possível captarmos o cenário em que o Serviço Social é demandado em razão das classes sociais emergentes: a burguesia (industrial) e o proletariado. Trata-se de uma profissão gestada e desenvolvida em resposta ao desenvolvimento do capitalismo industrial e cujos profissionais, atuando no processo de trabalho coletivo, situam-se no interior da divisão social do trabalho. O assistente social participa do processo de reprodução das classes sociais e do relacionamento contraditório entre elas. Ao mencionarmos isso, não significa que focalizamos a reprodução restrita ao campo específico das relações de produção, mas também no que daí se desdobra, ou seja, o que se vincula à produção/reprodução da subjetividade, da vida social em geral. Ao atuar no processo de reprodução das relações sociais entre as classes, o assistente social encontra-se em um campo em que lhe cabem respostas aos interesses das classes, ao mesmo tempo que também responde pela sua sobrevivência, uma vez que é partícipe da classe trabalhadora. Embora o profissional de Serviço Social não se vincule diretamente à produção, é um profissional que participa, ao lado de outras profissões, da implementação de condições necessárias ao processo de reprodução no seu conjunto, já que parte da divisão social (e técnica) do trabalho.

Esse é o "solo histórico" de origem do Serviço Social, cuja gênese, no Brasil, encontra-se na década de 1930. Uma profissão que, não obstante atualmente manifestar referências progressistas e democráticas, foi suscitada no processo de desenvolvimento industrial do Brasil, tendo como base ideológica fundamental o pensamento social conservador da Igreja católica. Nesse processo, o 
Estado e o empresariado passaram a demandar o trabalho dos assistentes sociais como uma espécie de agentes interventores da "questão social", através da participação no processo de execução das políticas sociais.

Dessa maneira, o trabalho do assistente social, mostrando diferentes tendências ao longo da História, é encontrado em diversas políticas sociais. Todavia, se esse trabalho já merecia ser observado em face da sua inerente complexidade, atualmente essa foi exacerbada, haja vista a intensificação dos problemas sociopolíticos e econômicos brasileiros, após a ampla penetração das diretrizes neoliberais ${ }^{7}$ no nosso país, que por ora inclui um retrocesso escancarado dos direitos duramente conquistados pelos trabalhadores.

Sob a justificativa de incapacidade do keynesianismo frente à contenção de mais uma crise capitalista, na década de 1970, ressurge o ideário neolibe-

7 O neoliberalismo nasceu em torno do final da Segunda Guerra Mundial, nas regiões da Europa e da América do Norte, em um período em que estava sendo consolidado o Estado de bem-estar social. Configurou-se como uma reação teórica e política ao Estado intervencionista. Seu texto de origem: “O caminho da servidão”, de Friedrich Hayek, publicado em 1944, atacava o ideário keynesiano e defendia a retomada do liberalismo clássico, ou seja, o retorno do capitalismo livre de regras, alicerçado nos pensamentos de Adam Smith e David Ricardo, que, entre outros aspectos, contaria com a intervenção mínima do Estado na economia. No entanto, a longa onda expansiva que manteve o crescimento econômico até o final dos anos de 1960 e o estágio das lutas de classes (deflagradas, entre outros fatores, pelo papel da União Soviética na Segunda Guerra Mundial) impediram àquela época o desenvolvimento do ideário neoliberal e criaram as condições para a supremacia do keynesianismo. Esse sistema representou certos ganhos para os trabalhadores (ao menos nos países de economia central), elevando seu padrão de consumo, contando com o papel fundamental do Estado como articulador das funções políticas e econômicas. Pode ser dito que as reivindicações do movimento operário foram absorvidas de modo significativo, sob a forma de políticas sociais antecipatórias (seguridade social, saúde, educação, habitação etc.), que buscavam adequar os trabalhadores às exigências do capital no período. Esse processo econômico e político resultou no Welfare State, "claramente uma reforma - uma tentativa temporal e geopoliticamente situada, que visava combinar acumulação e diminuição dos níveis de desigualdade com alguma redistribuição de renda" (BEHRING; BOSCHETTT, 2011). Dessa maneira, houve uma onda expansiva de crescimento que se manteve até o final da década de 1960, quando começou a dar sinais de esgotamento. A década de 1970 caracterizou mais um período de crise capitalista ocasionada, entre outros fatores, pela superprodução e pelo subconsumo, pela crise do petróleo, pela política de pleno emprego e pela conquista de direitos trabalhistas. Esses fatores incidiram nos níveis de lucratividade do capital e foram propícios para a retomada com importante avanço das ideias neoliberais, que, até então, não haviam encontrado momento oportuno para prosperarem, em decorrência de um período de expansão sem precedentes no capitalismo, com base no binômio fordista-keynesiano. 
ral como a alternativa plausível, haja vista as propostas que objetivamente se dirigiam à atrofia das políticas de bem-estar social e, portanto, à desconstrução dos direitos humanos/sociais. Assim sendo, deparamo-nos, entre outras medidas, com a desregulamentação estatal, o abandono de políticas que visavam ao alcance do pleno emprego, a redução de gastos com a seguridade social e a ampliação da mobilização do capital almejando lucro, o que o leva a penetrar, cada vez mais, em países "periféricos". Tudo isso resulta na implantação de mudanças organizacionais - marcadas por uma profunda alteração na produção -, denominada reestruturação produtiva, cujos objetivos, entre outros, são a liberação do trabalho (vivo) em grande escala e a sua substituição pelo trabalho morto, como mecanismo em prol da recuperação dos lucros.

A mencionada lógica econômica e produtiva efetivou um rearranjo na vida social. Redesenhou a correlação de forças entre os governos, o capital e o trabalho, com consequentes impactos sobre a classe trabalhadora, suscitando importantes prejuízos na vida social, mesmo em países/regiões em que as políticas sociais já mereciam ser observadas pela incipiência, como o Brasil. Em linhas gerais, pode ser mencionado que o Estado reduziu drasticamente as políticas sociais passando à sua focalização nos mais pauperizados e, desse modo, um número cada vez maior de pessoas foi lançado à extrema pobreza. A partir daí, assistimos à escalada dos programas de ajustes estruturais e à desconstrução dos direitos humanos/sociais. Sob a primazia do capital financeiro, o processo de reestruturação do capital afetou direta e significativamente o âmbito do trabalho, em um movimento em curso que se assenta na culpabilização dos trabalhadores pela crise capitalista contemporânea, ao mesmo tempo que coloca sobre seus ombros a responsabilidade de superá-la, criando o que Mota (1995) denominou uma "cultura da crise". Como parte desse processo, há um movimento de mundialização da economia marcado pela importante mobilidade e/ou fuga de capitais e plantas produtivas para regiões onde os incentivos fiscais e o nível da organização ou, melhor, da desorganização operária mostram-se mais favoráveis para a obtenção de altos lucros (CHESNAIS, 1996).

Nesse contexto, os defensores da liberalização da economia têm uma relação pragmática com o Estado, na medida em que não afastam a sua intervenção, desde que voltada a seus interesses. Ou seja, é desejável um Estado forte do ponto de vista econômico e fraco em relação à proteção social. Em um cenário de significativo avanço neoliberal, os interesses do capital financeiro adquirem primazia dentro do Estado. As expressões da "questão social", resultan- 
tes desse processo, são despolitizadas e tratadas por meio de "fórmulas tecnicistas", haja vista a retração das políticas sociais. Além disso, a precarização das condições de trabalho é indubitável. Dessa maneira, parece-nos inconteste que indagações e apreciações acerca do trabalho de um profissional que lida com políticas sociais diante de diferentes expressões da "questão social", como o assistente social, por exemplo, tornem-se urgentes.

Diante desse quadro, considera-se relevante, inclusive, a preocupação com aqueles que se encontram em formação para graduarem-se nessa área. Como esses futuros profissionais vivenciam esse processo? Daí o porquê de, também, voltarmos nossa atenção à relação entre as condições de trabalho dos supervisores de campo e a formação profissional dos estagiários do espaço sócio-ocupacional em que realizamos pesquisa: o sistema penal. Em uma das variáveis da nossa pesquisa, buscamos captar como os estagiários de Serviço Social consideravam sua vivência no estágio, em face das exigências à formação profissional, em um dos campos sócio-ocupacionais tradicionais da profissão e avaliado como o mais ou um dos mais complexos, haja vista as marcas da repressão e da punição e as recorrentes menções, até pela "grande mídia", de suas precárias condições de trabalho e flagrantes violações aos direitos humanos, particularmente no contexto que ora experimentamos no Brasil. Ou seja, interessávamo-nos em perceber, partindo das considerações dos referidos estagiários, se e como a experiência de estágio supervisionado nesse local era por eles captada como compatível com as referências e exigências das normativas para formação profissional em Serviço Social.

O Serviço Social é uma área profissional que avalia como imprescindível a dimensão pedagógica da supervisão no estágio obrigatório, cujo referencial mostra-se democrático e progressista, alicerçado em fundamentos, valores, princípios e diretrizes substancialmente críticos à ordem instituída. Como já explicitado, aqui apenas poderemos aludir a alguns poucos dados da pesquisa. Além disso, mencionamos tratar-se de um campo de estágio em que há muito existia a observação das precárias condições de trabalho, cabendo-nos, frente a tudo que dissemos, considerar a exacerbação disso no atual cenário nacional de evidente derrocada dos direitos sociais e ascensão dos apelos ao controle repressivo, à coerção e à punição; características institucionais que convivem com a assistência ao preso e ao internado (e familiares) que, segundo os artigos $10 \mathrm{e}$ 11 da Lei de Execução Penal - LEP (1984), objetiva prevenir o crime e orientar 
o retorno à convivência em sociedade, inclusive, extensivo ao egresso. ${ }^{8}$

\section{O sistema penal brasileiro: um dos espaços sócio-ocupa- cionais e de formação, por meio do estágio supervisiona- do, de assistentes sociais}

Não obstante observarmos alusões à garantia de direitos como finalidade dos órgãos executores da política criminal, como o DEPEN, o CNPCP, o CNJ e do disposto na LEP, ${ }^{9}$ não nos é possível deixar de reconhecer que o sistema penal nacional, como já mencionado, mostra-se, até pela expressão da grande mídia, violador dos direitos dos custodiados, o que pode ser concluído se partirmos apenas do quesito superpopulação carcerária, que ultrapassa de maneira importante o número de vagas disponibilizadas, conforme o gráfico 1.

8 Ratificamos que, em decorrência da exigência de sigilo aos dados institucionais, evitaremos indicar nomes e sujeitos, o que não obscurecerá a compreensão dos resultados que alcançamos por meio do trabalho.

9 Em nosso país, o órgão executivo responsável pelo controle e aplicação da Lei de Execução Penal (Lei 7.210/84) e das diretrizes da Política Penitenciária Nacional é o Departamento Penitenciário Nacional (DEPEN). Segundo a referida instituição, que é vinculada ao Ministério da Justiça e Segurança Pública, cabe-lhe a missão de induzir, apoiar e atuar na execução penal brasileira, promovendo a dignidade humana, com profissionalismo e transparência, com vistas a uma sociedade justa e democrática. Além disso, cabe-lhe ser reconhecido como órgão fomentador da correta execução penal e da plena garantia dos direitos fundamentais de todos os seres humanos envolvidos no fenômeno criminoso. O Conselho Nacional de Política Criminal e Penitenciária - CNPCP, instituído em 1980, é um dos órgãos da execução penal. Tem sede na capital da República e também é subordinado ao Ministro da Justiça. Em consulta à sua exposição de motivos, verificamos que expõe que presta valioso contingente de informações, de análises, de deliberações e de estímulo intelectual e material às atividades de prevenção da criminalidade. Preconiza em todo o território nacional uma nova política criminal e penitenciária a partir de periódicas avaliações do sistema criminal, criminológico e penitenciário, bem como a execução de planos nacionais de desenvolvimento quanto às metas e prioridades da política a ser executada (DEPEN, 2019). Quanto ao Conselho Nacional de Justiça - CNJ (CNJ, 2019), pudemos verificar que é exposto tratar-se de uma instituição pública que visa aperfeiçoar o trabalho do sistema judiciário brasileiro, principalmente no que diz respeito ao controle e à transparência administrativa e processual. Dessa maneira, é dito que lhe cabe desenvolver políticas judiciárias que promovam a efetividade e a unidade do Poder Judiciário, orientadas para os valores de justiça e paz social, visando impulsionar a efetividade da Justiça brasileira. 
Gráfico 1. Pessoas privadas de liberdade segundo número e déficit de vagas: Brasil, 2010 a 2017

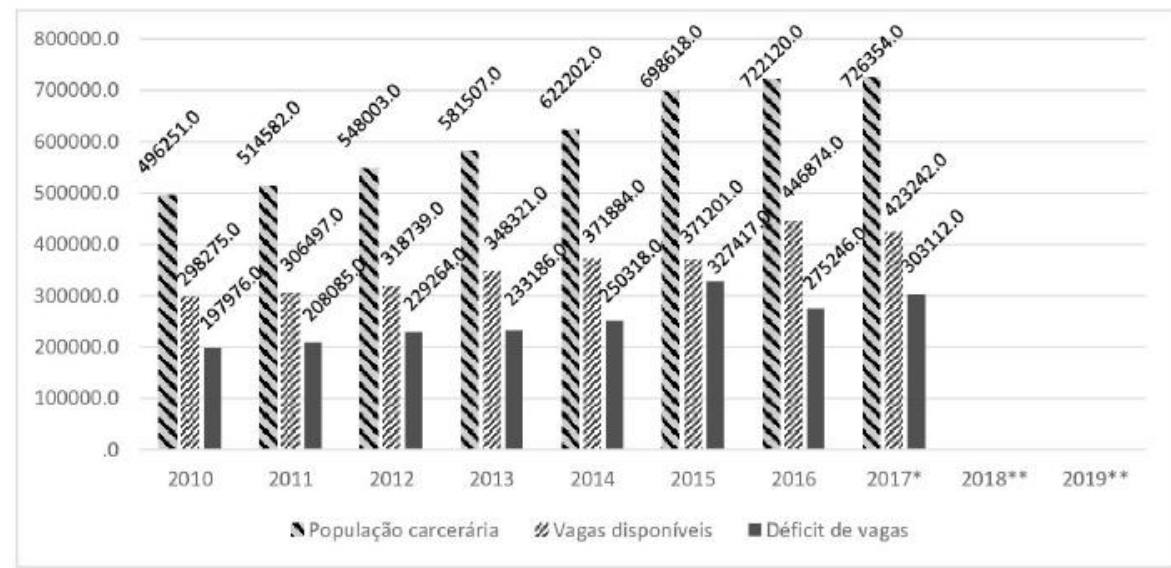

* Dados disponíveis, apenas, até o mês de junho de 2017;

** Dados indisponíveis.

Fonte: gráfico elaborado pelas autoras a partir de Levantamento Nacional de Informações Penitenciárias (2017).

Em relação à população carcerária, a ampliação numérica é notável no Brasil. Em 2015, ${ }^{10}$ o país, com 698.618 pessoas presas, alcançou a marca de terceira maior população prisional do mundo, atrás apenas dos Estados Unidos e da China (DEPEN, 2018).

Não é difícil observar que o cenário de acelerado crescimento da população carcerária relaciona-se à implementação de políticas de cariz neoliberal. Tais políticas incidem no Estado, atrofiando os mecanismos de proteção social e sobrelevando o aparato coercitivo para regular as consequências disso. $\mathrm{Ou}$ seja, em vez de o Estado legitimar-se pela efetivação de direitos sociais, que caracteriza o Estado social, a atrofia dos mecanismos de proteção suscita uma es pécie de Estado penal, em que o "controle punitivo" prevalece como meio pertinente de regulação da insegurança social suscitada pelo consequente aumento do nível de miséria/desigualdade social.

Deparamo-nos com um contexto de ataque aos direitos dos trabalhadores, no qual, ao lado do avanço punitivo do "Estado penal", parcas políticas de proteção social se dirigem, de maneira focalizada, aos mais pauperizados.

${ }^{10}$ Neste período, realizávamos as entrevistas na secretaria penal do Rio de Janeiro. 
Nesse processo, as expressões da "questão social"11 são identificadas como manifestações de desordem social e enfrentadas de forma repressiva, como mero "caso de polícia", por exemplo. Uma verdadeira expressão de "moralismo e panoptismo punitivo" que toma os pobres como alvo de uma espécie de necessária vigilância social permanente, em decorrência da suposição de representarem possibilidade significativa de ameaça social. Isso, inclusive, alicerça as ações repressivas do Estado, que conta com o recurso de certos meios de comunicação para legitimá-las. Nesse processo, a prisão é difundida como alternativa inquestionável, pois mostrada como se, após se ter lançado mão de relevantes e incontáveis recursos - ou seja, após "inúmeros percursos trilhados" - se tornasse o último recurso possível. A prisão incorpora o significado de "última trincheira possível", diante de um mundo inóspito e inseguro (WACQUANT, 2008, 2015). É uma estratégia que parece buscar camuflar o real motivo da crescente precarização das condições de trabalho e de vida do segmento social que vive do (próprio) trabalho e da decorrente ampliação da violência urbana, uma vez que embaça as consequências de uma sociabilidade assentada na recorrente perda de direitos essenciais, portanto, assentada no aprofundamento da desigualdade social, que caracteriza o atual contexto de desemprego estrutural, de dessocialização do trabalho. Também é uma estratégia que pretende ser mecanismo capaz de garantir a ordem, reafirmando a autoridade do Estado na vida cotidiana. Nisso pode ser observada, inclusive, a tentativa de neutralizar reações da classe trabalhadora avaliadas como desestabilizadoras, desagregadoras, seja pela via das repressões a ações individuais ou da criminalização dos movimentos sociais.

Pode ser dito que vivemos em um contexto de incremento de uma política penal com a utilização de investimentos milionários no Sistema de Justiça Criminal que, no Brasil, abrange órgãos dos poderes executivos e judiciários, em todos os níveis da federação. O sistema é organizado em três linhas principais: segurança pública, justiça criminal e execução penal (IPEA, 2008) e alcança a atuação do poder público desde a repressão das infrações até a aplicação

${ }^{11}$ Com base em Iamamoto e Carvalho (1996, p. 128), cabe-nos mencionar que, se as expressões da "questão social" decorrem da formação da classe operária e sua entrada no cenário político, haja vista a necessidade de seu reconhecimento pelo Estado, ou seja, a exigência de implementação de políticas que, de alguma forma, considerassem seus interesses, podemos inferir que, atualmente, o Estado sob a perspectiva neoliberal, à medida que passou a reduzir significativamente os investimentos em políticas públicas, lançando mão de medidas coercitivas (que, em verdade, nunca abandonou), empurrou um grande contingente de pessoas à miséria, aumentando em número e diversidade as referidas expressões da denominada "questão social". 
das penas com a articulação das três esferas. A eficiência das atividades da Justiça Comum, por exemplo, depende da atuação da polícia, que, por sua vez, é chamada a agir quando se trata do encarceramento em massa da população mais pobre, um fenômeno que, ao analisar, especialmente, a atual sociedade norte-americana, Wacquant $(2008,2015)$ denominou criminalização da pobreza, mas que analogamente se observa, salvaguardadas especificidades, na realidade latino-americana, aqui considerando o Brasil. Quanto a isso, é importante apreciarmos, inclusive, que o autor explicita que "as mesmas pessoas que exigem um Estado mínimo, a fim de 'liberar' as 'forças vivas' do mercado [...], não hesitam em erigir um Estado máximo para assegurar a 'segurança' no cotidiano" (WACQUANT, 2015, p. 48).

Diante do exposto, cabe-nos considerar que em nosso país a grandiosidade do número de desempregados é encontrada ao lado de um acelerado crescimento da população carcerária brasileira, como já indicado no Gráfico 1, o que é verificável no estado do Rio de Janeiro, à exceção de uma discreta diminuição entre os anos de 2016 e 2017, conforme gráfico 2 abaixo:

Gráfico 2 - Pessoas privadas de liberdade: estado do Rio de Janeiro, 2010 a out. 2019

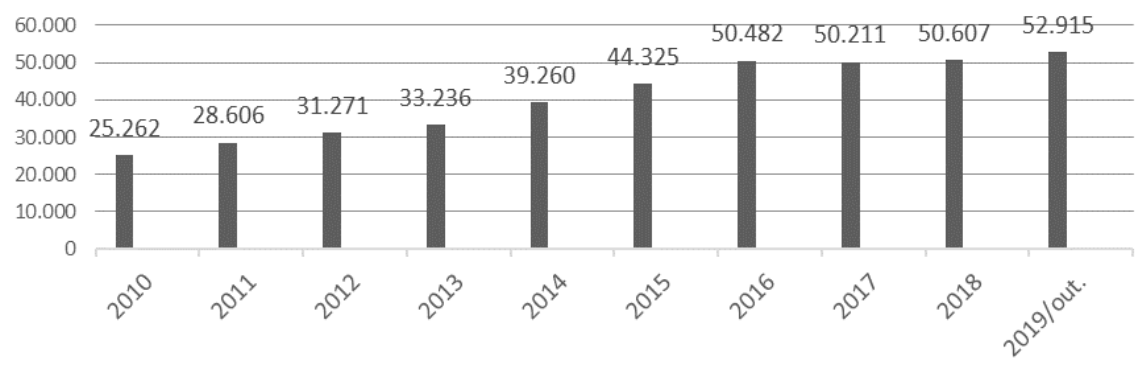

Fonte: gráfico elaborado pelas autoras a partir de dados obtidos na Coordenação de Serviço Social da SEAP-RJ, em 2019, por meio da pesquisa Ética, direitos, trabalho e Serviço Social: um estudo no sistema penal.

Cabe-nos destacar que, a partir da desativação das carceragens das delegacias do estado, por determinação da Secretaria de Segurança em atenção à recomendação do Conselho Nacional de Justiça, vem ocorrendo um importante aumento da população custodiada no sistema penal do Rio de Janeiro, conforme observa-se no Gráfico 2. A custódia no sistema penitenciário nacional não se resume à guarda de pessoas em situação de privação de liberdade. A Lei de 
Execução Penal (BRASIL, 1984 - grifo nosso), que expõe como objetivo "efetivar as disposições de sentença ou decisão criminal e proporcionar condições para a harmônica integração social do condenado e do internado", prevê, nos artigos $10 \mathrm{e}$ 11, a assistência aos presos. Não obstante, há evidente insuficiência no que se refere à assistência aos presos, haja vista que, além da inadequação dos espaços físicos em face da superlotação, há, entre outros aspectos, escassez de trabalhadores da área denominada Tratamento Penitenciário, que agrega assistentes sociais, psicólogos, médicos etc., aspecto que caracteriza a tendência do atual contexto neoliberal de ataque às políticas sociais e consequente atrofia dos direitos sociais. Isso deve ser considerado em face dos espaços historicamente destinados à execução de penas, à punição, em um momento em que o clamor social punitivo mostra significativos apelos de privação de liberdade.

Como dissemos, entre os trabalhadores do Tratamento Penitenciário, destacamos, no estado do Rio de Janeiro, ${ }^{12}$ os assistentes sociais, cuja história teve início na década de 1950 e, nos últimos anos, vêm sofrendo com a redução dos postos de trabalho e com o fenômeno denominado precarização das relações de trabalho, que ataca os exíguos direitos duramente conquistados pelos trabalhadores em geral e, salvaguardadas especificidades, pelos diferentes ramos de trabalho. Ou seja, os assistentes sociais experimentam a tensão de um contexto cujas alterações impostas pelas políticas neoliberais ao âmbito do trabalho implicam a redução dos postos de trabalho e direitos trabalhistas. Isso evidentemente afeta o âmbito da execução penal e os trabalhadores inseridos na área. Além do desemprego e da sua ameaça, há o avanço da precarização dos vínculos de trabalho por meio da contratação temporária e dos cargos comissionados. Dessa maneira, enquanto em 2010 havia, no sistema penitenciário do estado do Rio de Janeiro, 99 assistentes sociais, entre os quais 52 eram estatutários, dois comissionados e 45 contratados temporariamente, em 2018 havia 42 assistentes sociais, sendo 34 estatutários, 5 contratados e 3 comissionados; atualmente, 2019, há o total de 38 assistentes sociais, apenas, sendo quatro deles comissionados. Isso implica diretamente nas condições de trabalho dos assistentes sociais, que, como já referido, participa do trabalho coletivo - é partícipe do processo de produção e reprodução das relações sociais.

\footnotetext{
${ }^{12}$ De acordo com Pereira (2006), o cenário penitenciário carioca, compromissado com a ordem e a segurança, recebe o tratamento penal como coadjuvante que preenche o vazio institucional, em face das assistências previstas no art. 11 da Lei de Execução Penal. Além disso, o termo utilizado "Tratamento Penal" se perfila à concepção da criminologia positivista e se refere à recuperação do sujeito infrator, e não aos condicionantes que levam à prisão.
} 
O último concurso público para o quadro efetivo de assistente social, no Rio de Janeiro, sob regime estatutário e amparado pelo Decreto 2479/79, ocorreu no ano de 1998 e, desde então, a secretaria do sistema penal do Rio de Janeiro tem utilizado contratos temporários e, em menor número, cargos em comissão como estratégia para a manutenção das atividades na assistência aos presos e às famílias. Esse cenário está relacionado ao que Behring (2008) qualifica como contrarreforma do Estado brasileiro e é materializado, fundamentalmente, pelo Art. 37, inciso IX da Constituição Federal Brasileira (BRASIL, 1988), em que está prevista a contratação por tempo determinado, para atender à necessidade excepcional e temporária de interesse público.

Todavia, se o sistema penal do Rio de Janeiro já merecia ser observado em razão de gerir um grande quantitativo de miseráveis e gerar um aumento de emprego no setor de bens e serviços carcerários, um setor caracterizado por postos de trabalho precários (FORTI, 2016), para o Serviço Social isso vem se tornando ainda pior, uma vez que, ao lado do significativo aumento da população carcerária, os profissionais dessa área vão sendo extintos, aumentando as dificuldades de atendimento à população carcerária (e familiares) em face do exíguo número de profissionais que lá permanecem.

Não é difícil inferir que o que foi dito pode prejudicar sobremaneira a qualidade do trabalho e, portanto, dos serviços prestados pelos profissionais de Serviço Social, violando valores, princípios e diretrizes cujas referências são caras ao trabalho e à formação dos assistentes sociais. Conforme já indicado, até mesmo as formas de contratação precárias vêm sendo extintas. Os últimos contratos temporários celebrados em 2013 tiveram a vigência encerrada em meados de 2018, sem novas contrações ou realização de concurso para o quadro efetivo, o que impõe sério risco à continuidade das ações dos assistentes sociais. Como demonstrativo da situação comentada, cabe-nos citar o fato de 25 unidades do sistema penitenciário do estado do Rio de Janeiro não disporem de profissionais de Serviço Social para a assistência prevista na Lei de Execução Penal e nas diretrizes da Política Penitenciária Nacional do Departamento Penitenciário Nacional. Ou seja, nesse âmbito, nem o trabalho via precarização vem sendo garantido pelo Estado.

Além da precarização dos vínculos trabalhistas dos assistentes sociais e do enxugamento do quadro funcional, o processo de invisibilidade desses profissionais, no nosso entender, foi levado ao extremo, quando foram retirados da estrutura do sistema penitenciário carioca, no ano de 2010, passando à estrutura da Secretaria de Estado de Fazenda (SEFAZ). O retorno só ocorreu no mês de julho de 2019, através da Lei 8.436/19, após mobilização da categoria profissio- 
nal. A progressão na carreira, prevista em lei, não vem ocorrendo e está impedida pelo Regime de Recuperação Fiscal (Lei Complementar Federal 157, de 2017), que está em vigência no Rio de Janeiro para sanear as contas públicas decorrentes das dívidas do estado junto ao governo federal, num contexto de suposta crise financeira, que se arrasta desde o ano de 2015. Os vencimentos dos assistentes sociais estão congelados há anos e defasados em relação aos profissionais que atuam na instituição na área de segurança (inspetores penitenciários), que, apesar de menor exigência escolar, pois o referido cargo exige nível médio, têm salários maiores que os assistentes sociais, cuja exigência é nível superior, o que é consoante ao avanço do que é denominado por Wacquant (2008, 2015) Estado penal, que na lógica neoliberal prioriza medidas de segurança em detrimento de outras de cunho social para lidar com as expressões da "questão social". Dessa maneira, pode ser apreciado que, nessa lógica, em direção oposta à redução de profissionais de Serviço Social, está o aumento da população carcerária no estado do Rio de Janeiro, ${ }^{13}$ conforme pode ser observado na próxima tabela 1:

Tabela 1. Efetivo carcerário e número de assistentes sociais: estado do Rio de Janeiro, 2010 a 2019.

\begin{tabular}{lcc}
\hline \hline Ano & Efetivo Carcerário (N) & Assistentes Sociais $(\mathbf{N})$ \\
\hline \hline $\mathbf{2 0 1 0}$ & 25.260 & 99 \\
$\mathbf{2 0 1 1}$ & 28.606 & 98 \\
$\mathbf{2 0 1 2}$ & 31.271 & 94 \\
$\mathbf{2 0 1 3}$ & 33.236 & 80 \\
$\mathbf{2 0 1 4}$ & 39.260 & 75 \\
$\mathbf{2 0 1 5}$ & 44.325 & 76 \\
$\mathbf{2 0 1 6}$ & 50.482 & 73 \\
$\mathbf{2 0 1 7}$ & 50.211 & 68 \\
$\mathbf{2 0 1 8}$ & 50.607 & 42 \\
$\mathbf{2 0 1 9}$ & 52.915 & 38 \\
\hline \hline
\end{tabular}

Fonte: tabela elaborada pelas autoras a partir de dados obtidos na Coordenação de Serviço Social da SEAP-RJ, em 2019, por meio da pesquisa Ética, direitos, trabalho e Serviço social: um estudo no sistema penal

${ }^{13}$ Se desde o início já podia ser observada a enorme desproporcionalidade entre o quantitativo de presos e o de assistentes sociais, é imprescindível alertarmos que não lhes cabe apenas o atendimento às pessoas presas, mas aos familiares também. Hoje cerca de 90.000 (noventa mil) familiares estão credenciados como visitantes. 
Evidentemente, as questões aqui abordadas repercutem na formação dos discentes que são lotados em instituições penais para realização de estágio obrigatório.

Em parte, essa afirmativa poderá ser aqui considerada, na medida em que apreciarmos alguns dados extraídos do subprojeto de pesquisa que inicialmente mencionamos. Na primeira dimensão desse subprojeto, realizamos, em 2015, 12 entrevistas com estagiários de Serviço Social. Apesar de termos a pretensão de prosseguirmos com estagiários dos anos sequentes, não pudemos cumprir nosso intuito, uma vez que a secretaria penal do estado do Rio de Janeiro interrompeu o estágio em Serviço Social e só deverá retomar tal atividade em 2020.

Quanto aos entrevistados, eram alunos de diferentes instituições de ensino de graduação em Serviço Social, com o estágio em curso, diferentemente dos outros entrevistados que abordaremos adiante, na segunda dimensão do subprojeto, que já tinham concluído o estágio obrigatório. Dessa maneira, entre os 12 entrevistados, nove cursavam graduação em instituições públicas de ensino, três deles participaram de projetos de iniciação científica (IC) e todos identificaram a teoria social marxista como vertente do pensamento predominante na orientação pedagógica do seu curso de graduação. Ao avaliarem a possibilidade de se tornarem profissionais na sua instituição de estágio, dois expressaram total desinteresse em serem profissionais neste campo, outros três mencionaram que só trabalhariam profissionalmente na área penal em caso de extrema necessidade e os demais consideraram possível. Com exceção de um estagiário, os demais entrevistados expressaram considerar que as condições de trabalho do assistente social/supervisor interferiam de maneira importante no processo de supervisão. Quanto a isso, destacaram, prioritariamente: a) a atual intensificação do trabalho, que é agravada pela precariedade dos vínculos empregatícios, os quais, além de poderem suscitar a descontinuidade do trabalho pelo término dos contratos e hierarquizarem os trabalhadores, os tornam vulneráveis, uma vez que, sob ameaça de desemprego, são compelidos à realização desenfreada de atendimentos aos presos e seus familiares, o que tende a prejudicar a qualidade dos serviços prestados pela instituição e a fazer com que o estagiário sinta prejuízo na inerente dimensão pedagógica do estágio. Existem até períodos em que os estagiários avaliam que há tendência em considerá-los possíveis substitutos dos profissionais, em decorrência do exíguo número de profissionais e/ou da ausência pela não contratação; b) as precárias condições do ambiente físico reservado ao trabalho dos assistentes sociais, que, além de tornar, por assim dizer, naturalizado o desrespeito a princípios profissionais fundamentais, inclui 
dificuldades importantes à supervisão, tais como calor excessivo, desrespeito ao sigilo, equipamentos sucateados e/ou ausência de equipamentos/materiais essenciais ao trabalho; e c) a fragilidade do debate teórico indispensável ao processo de análise da realidade, e suas inerentes particularidades, experimentada pelo estagiário na instituição, o que, grande parte, decorre da intensificação do trabalho e da desarticulação entre a supervisão acadêmica e a supervisão de campo.

Voltamos nossa atenção para as considerações de ex-alunos sobre a questão do estágio para a formação profissional no espaço sócio-ocupacional em questão. Na segunda dimensão do subprojeto, citamos termos entrevistado cinco egressos, recém-formados, do curso de graduação em Serviço Social em 2015, pois foram os que conseguimos identificar como ex-estagiários do sistema penal do estado do Rio de Janeiro, em determinada unidade de ensino pública do mesmo estado, ${ }^{14}$ que expressa alinhar seu projeto pedagógico às Diretrizes Curriculares da Associação Brasileira de Ensino em Serviço Social (ABEPSS), ao Plano Nacional de Estágio (PNE) e aos fundamentos críticos do atual Projeto Ético Político do Serviço Social. ${ }^{15}$ Os entrevistados eram do gênero feminino e, inicialmente, expressaram significativas dificuldades na relação com alguns outros profissionais do gênero masculino que trabalhavam no local do seu estágio. Tal menção, pelo que pudemos captar, decorre da tradição repressiva e até, se pode dizer em linhas gerais, em que predomina uma cultura que caracteriza tendências consideradas tradicionalmente masculinas e conservadoras - uma cultura que privilegia certos traços tidos como inerentes ao gênero masculino, símbolo de força como representação de superioridade, pressupondo, em consequência, certa imagem de mulher e de "profissão feminina". Todos entrevistados disseram ter ido para tal campo de estágio por interesse próprio. Não obstante, dois afirmaram que, após terem realizado estágio no local, não pretendiam atuar profissionalmente na área, em decorrência da verificação da precariedade dos contratos, das condições de trabalho e dos baixos salários. Ao comentarem sobre a interferência das condições de trabalho em face da exigência de supervisão no estágio, todos disseram que o excesso de solicitações dirigidas ao assistente social/supervisor dificultava muito e/ou inviabilizava o acompanhamento das atividades dos estagiários. No que se refere às referências do atual Código de Ética e do atual Projeto Profissional Crítico, os entrevistados expressaram certo conhecimento dos seus fundamentos e destaca-

${ }^{14}$ Não identificaremos a instituição de ensino em decorrência do necessário sigilo.

${ }^{15} \mathrm{O}$ código de ética profissional do assistente social vigente é elemento destacado do citado projeto, uma vez que é referência direta ao trabalho profissional. 
ram suas relevâncias. Todavia, sublinhando as condições de trabalho adversas no espaço sócio-ocupacional abordado, argumentaram justificando a inexistência de meios adequados para assegurar ações alinhadas às referidas balizas profissionais, mesmo que apareçam em algumas respostas alusões a certo esforço do(s) supervisor(es) nesse sentido. Isso traz à tona a polêmica do "possibilismo", em face das normativas profissionais e do atual Projeto Profissional Crítico. Leva-nos à reflexão acerca de a formação no estágio supervisionado limitarse a uma espécie de crítica impotente quanto a condições de trabalho avaliadas adversas, podendo naturalizá-las, em vez de viabilizar análises críticas que desvelem a realidade que as suscitam em prol da possibilidade de, consequentemente, emergirem estratégias profissionais pertinentes, capacitando o futuro profissional frente às balizas profissionais citadas, especialmente neste momento em que a tensão em face da alternativa de objetivações democráticas e progressistas é recrudescida em nossa sociedade. Diante disso, saliente-se que a prestação de serviços qualificados aos usuários e a defesa intransigente dos direitos humanos são compromissos assumidos pelos profissionais do Serviço Social.

Há de ficar claro que, como mencionamos em princípio, o estágio curricular é atividade que deve comportar as necessárias reflexões teórico-práticas que também fundamentarão e poderão servir de parâmetros às ações dos futuros profissionais, e isso supõe, portanto, responsabilidade/possibilidade profissional diante do processo de supervisão, que, não sendo o único responsável por isso, deve contribuir de maneira importante com a formação profissional qualificada para a prestação de serviços aos usuários das instituições empregadoras. Aliás, esse conteúdo vincula-se ao exigido pelo X Princípio Fundamental do Código de Ética Profissional vigente. ${ }^{16}$ O Serviço Social é um segmento das ciências sociais em que o trabalho dirigido ao atendimento de diversos sujeitos que procuram diferentes instituições em busca de saciar alguma necessidade é característica e proeminente. Dessa maneira, ao futuro profissional cabe a possibilidade de adquirir sustentação teórico-crítica, ético-política e operacional suficiente para muni-lo de recursos em favor de tal exigência. Portanto, como considerar a formação profissional sem que a ela seja possibilitada a reflexão apropriadamente sobre as determinações da realidade social, que incluem as condições de trabalho dos assistentes sociais e da vida social em geral e, particularmente, em um espaço sócio-ocupacional em que traços inerentes à desigual-

${ }^{16} \mathrm{X}$ Princípio Fundamental: Compromisso com a qualidade dos serviços prestados à população e com o aprimoramento intelectual, na perspectiva da competência profissional (BRASIL, 2012). 
dade social se mostram exacerbados? Será que a não problematização pertinente das condições de trabalho, suas possibilidades e limites profissionais suscitam nos estagiários a referida visão "possibilista", em face das normativas que comportam os valores e princípios fundamentais do Serviço Social? Qual a valorização da orientação de campo e acadêmica para os assistentes sociais? Em que medida o imediatismo, o praticismo e o produtivismo vêm sendo aspectos enfrentados e debatidos nos encontros de supervisão? Qual o papel da teoria, para uma profissão interventiva como o Serviço Social?

Por fim, será que o que aqui abordamos ilumina, mesmo que parcialmente, o porquê da recorrência, entre os estagiários entrevistados e entre significativa parcela profissional do Serviço Social, do falso dilema "na prática, a teoria é outra"?

\section{Referências}

BEHRING, E. R.; BOSCHETTI, I. Política social: fundamentos e história. 9. ed. São Paulo: Cortez, 2011.

BEHRING, E. R. Brasil em contra-reforma: desestruturação do Estado e perda de direitos. 2. ed. São Paulo: Cortez, 2008.

BRASIL. Constituição (1988). Constituição da República Federativa do Brasil. Brasília, DF: Presidência da República. Disponível em: $<$ http://www.planalto.gov.br/ccivil_03/constituicao/constituicao.htm.> Acesso em: 12 jan. 2020.

. Lei no 7210, de 11 de julho de 1984. Institui a Lei de Execução Penal. Brasília, DF: Presidência da República. Diário Oficial da União. Disponível em: < http://www.planalto.gov.br/ccivil 03/leis/17210.htm.> Acesso em: 15 jan. 2020.

. Conselho Federal de Serviço Social - CFESS. Código de ética do/a assistente social: Lei 8662/93.10². Ed. Brasília, DF: CFESS, 2012. Disponível em: < http://www.cfess.org.br/arquivos/CEP_CFESS-SITE.pdf. $>$ Acesso em: 22 jan. 2010.

CHESNAIS, F. A mundialização do capital. São Paulo: Xamã, 1996.

CONSELHO NACIONAL DE JUSTIÇA - CNJ. Quem somos. Brasília, DF, [2020]. Disponível em: <https://www.cnj.jus.br/sobre-o-cnj/quem-somos-evisitas/.> Acesso em: 14 de out. 2019. 
DEPARTAMENTO PENITENCIÁRIO NACIONAL - DEPEN. SisDepen: Informações penitenciárias consolidarão base de dados nacional. Notícias. Brasília, DF, 2018. Disponível em: < https://www.depen.gov.br/DEPEN/noticias-1/noticias/sisdepen-informacoes-penitenciarias-consolidarao-base-dedados-nacional. $>$ Acesso em: 9 mar. 2019.

\section{Conselho Nacional de Política Criminal e Penitenciária -}

CNPCP. Brasília, DF, [2020]. Disponível em: < http://depen.gov.br/ DEPEN/depen/cnpcp.> Acesso em: 23 set. 2019

FILHO, G. S. A “questão social” no Brasil. Rio de Janeiro: Civilização Brasileira, 1982.

FORTI, V. Ética, crime e loucura: reflexões sobre a dimensão ética no trabalho profissional. Rio de Janeiro: Lumen Juris, 2016.

IAMAMOTO, M. V.; CARVALHO, R. Relações sociais e Serviço social no Brasil: esboço de uma interpretação histórico-metodológica. 11. ed. São Paulo: Cortez/Celats, 1996.

LEVANTAMENTO NACIONAL DE INFORMAÇÕES

PENITENCIÁRIAS - INFOPEN. Ministério da Justiça e Segurança Pública.

Infopen. Brasília, DF: Departamento Penitenciário Nacional, 2017. Disponível em: < http://depen.gov.br/DEPEN/depen/sisdepen/infopen/relatorios-sinteticos/relatorios-sinteticos. $>$ Acesso em: 6 out. 2019.

INSTITUTO DE PESQUISA APLICADA - IPEA. Sistema de Justiça Criminal no Brasil: quadro institucional e um diagnóstico de sua atuação. Brasília, 2008. Disponível em: <http://www.ipea.gov.br/portal/images/stories/ PDFs/TDs/td 1330.pdf.> Acesso em: 10 jan. 2020.

LUKÁCS, G. As bases ontológicas da atividade humana. In: Revista Temas de Ciências Sociais. São Paulo, no 4, p. 1-18, 1978.

. Para uma ontologia do ser social. São Paulo: Boitempo, 2012.

MOTA, A.E. Cultura da crise e seguridade social. São Paulo: Cortez, 1995.

NET'TO, J. P. O Serviço Social e a tradição marxista. Serviço Social e Sociedade. São Paulo, n. 30, Ano X, p. 89-102, mar./ago. 1989.

Capitalismo monopolista e Serviço Social. 3. ed. São Paulo: Cortez, 2001. 
PEREIRA, T.M.D. O guarda espera um tempo bom: a relação de custódia e o ofício dos inspetores penitenciários. Orientadora: Suely Souza de Almeida.2006. Tese (Doutorado em Serviço Social) - Escola de Serviço Social, Universidade Federal do Rio de Janeiro, Rio de Janeiro, 2006. Disponível em: $<$ http://www.ess.ufri.br. $>$ Acesso em: 1 set. 2019.

REVISTA Temporalis. Brasília, n. 3, ano 2, jan./jun. 2001.

WACQUANT, L. As duas faces do gueto. São Paulo: Boitempo, 2008

Punir os pobres: a nova gestão da pobreza nos Estados Unidos. Rio de Janeiro: Revan/Instituto Carioca de Criminologia, 2015. 